Andrews University

Digital Commons @ Andrews University

Faculty Publications

$1-1-2004$

\title{
Predicting Dynamics of Aggregate Loafing Behavior in Glaucous- winged Gulls (Larus glaucescens) at a Washington Colony
}

Shandelle M. Henson

Andrews University, henson@andrews.edu

James L. Hayward

Andrews University, hayward@andrews.edu

Christina M. Burden

Andrews University

Clara J. Logan

Andrews University, cllogan@andrews.edu

Joseph G. Galusha

Walla Walla University

Follow this and additional works at: https://digitalcommons.andrews.edu/pubs

Part of the Ornithology Commons

\section{Recommended Citation}

Henson, Shandelle M.; Hayward, James L.; Burden, Christina M.; Logan, Clara J.; and Galusha, Joseph G., "Predicting Dynamics of Aggregate Loafing Behavior in Glaucous-winged Gulls (Larus glaucescens) at a Washington Colony" (2004). Faculty Publications. 2047.

https://digitalcommons.andrews.edu/pubs/2047

This Article is brought to you for free and open access by Digital Commons @ Andrews University. It has been accepted for inclusion in Faculty Publications by an authorized administrator of Digital Commons @ Andrews University. For more information, please contact repository@andrews.edu. 


\title{
PREDICTING DYNAMICS OF AGGREGATE LOAFING BEHAVIOR IN GLAUCOUS-WINGED GULLS (LARUS GLAUCESCENS) AT A WASHINGTON COLONY
}

\author{
Shandelle M. Henson, ${ }^{1,4}$ James L. Hayward ${ }^{2}$ Christina M. Burden, ${ }^{2}$ \\ Clara J. Logan, ${ }^{1}$ and Joseph G. Galusha ${ }^{3}$ \\ ${ }^{1}$ Department of Mathematics, Andrews University, Berrien Springs, Michigan 49104, USA; \\ ${ }^{2}$ Biology Department, Andrews University, Berrien Springs, Michigan 49104, USA; and \\ ${ }^{3}$ Department of Biological Sciences, Walla Walla College, College Place, Washington 99324, USA
}

\begin{abstract}
Aвstract.-Seabirds move throughout the day in changing, patchy environments as they engage in various behaviors. We studied the diurnal abundance dynamics of Glaucous-winged Gulls (Larus glaucescens) in a habitat patch dedicated to loafing in the Strait of Juan de Fuca, Washington. We constructed three differential equation models as alternative hypotheses and then used model selection techniques to choose the one that most accurately described the system. We validated the model on an independent data set, made a priori model predictions, and conducted a field test of the predictions. Clear dynamic patterns emerged in the abundance of loafing gulls, even though individuals moved in and out of the loafing area more or less continuously throughout the day. Temporal patterns in aggregate loafing behavior are predicted by three environmental factors: day of the year, height of the tide, and solar elevation. This result is important for several reasons: (1) it reduces the aggregate behavior of complicated vertebrates to a simple mathematical equation, (2) it gives an example of a field system in which animal abundances are determined largely by low dimensional exogenous forces, and (3) it provides an example of accurate quantitative prediction of animal numbers in the field. From the point of view of conservation biology and resource management, the result is important because of the pervasive need to explain and predict numbers of organisms in time and space. Received 18 April 2003, accepted 9 December 2003.
\end{abstract}

Resumen. - Las aves marinas se mueven a lo largo del día a través de ambientes cambiantes y distribuidos en parches conforme realizan diferentes comportamientos. Nosotros estudiamos la dinámica de la abundancia diurna de gaviotas Larus glaucescens en un parche de hábitat dedicado al descanso en el estrecho de Juan de Fuca, Washington. Construimos tres modelos basados en ecuaciones diferenciales como hipótesis alternativas y después empleamos técnicas de selección de modelos para escoger el que mejor describía el sistema. Validamos este modelo usando datos independientes, hicimos predicciones a priori a partir del modelo y realizamos una prueba de dichas predicciones en el campo. Algunos patrones en la dinámica de la abundancia de las gaviotas que estaban descansando fueron claros, aunque algunos individuos se movieron hacia adentro y hacia afuera del área de descanso de forma más o menos continua a través del día. Los patrones temporales en el comportamiento de descanso agregado fueron predichos por tres factores ambientales: el día del año, la altura de la marea y la elevación del sol. Este resultado es importante por varias razones: (1) reduce el complicado comportamiento de agregación de los vertebrados a una simple ecuación matemática, (2) da un ejemplo de un sistema de campo en el que la abundancia de los animales está determinada en buena parte por fuerzas exógenas de pocas dimensiones y (3) provee un ejemplo de una predicción cuantitativa exacta de números de animales en el campo. Desde el punto de vista de la biología de la conservación y el manejo de los recursos, este resultado es importante debido a la imperiosa necesidad de explicar y predecir la abundancia de los organismos en el tiempo y en el espacio.

BIRDS MOVE FROM patch to patch in changing environments as they engage in behaviors that enhance fitness (Cooke and Ross 1972, DeWoskin 1980, Hunt and Schneider 1987, Wondolowski

${ }^{4}$ E-mail henson@andrews.edu
2002). Understanding environmental patch structure and predicting fluctuations in numbers of birds in those patches constitute important concerns of both avian ecologists and resource managers (Wiens 1976). For example, patch occupancy predictions would allow avian ecologists to test hypotheses regarding 
the effect of environmental variables on animal movement and would help resource managers to better assess habitat-specific risks to birds and ameliorate human-bird interference.

The quantitative analysis of spatial redistribution is a vigorous subdiscipline in ecology (Turchin 1998). Many studies are based on statistical or stochastic models and regression analyses. There are also many theoretical studies that use deterministic dynamic models (such as differential equations), but often those are not well-connected to data or successfully tested in the field. Deterministic prediction of the temporal dynamics of habitat patch occupancy requires an interdisciplinary methodology similar to that used in physics. In such a paradigm, deterministic mathematical models, such as differential equations, serve as crisp testable hypotheses; statistical techniques connect models to data; and experiments provide rigorous tests of model predictions. Few predictive studies of that type exist for organisms outside of the laboratory. Difficulties include the lack of adequate and appropriate data, impracticality of experimental manipulation and replication, and lack of validated mathematical models (Cushing et al. 1998, 2003). In the case of complex organisms such as birds, such difficulties are compounded by the increased flexibility of the behavior of individual animals.

The fundamental challenge in modeling ecological dynamics is the identification of scales at which random individual-level behaviors form patterns, and the mechanisms behind pattern formation (Hunt and Schneider 1987, Levin 1992, Silverman et al. 2001). In physics, randomness at the quantum level organizes into deterministic rules for the dynamics of larger objects. In a similar way, we might expect patterns in habitat patch occupancy to emerge for assemblages of birds, even though individual birds may move more or less independently or in small groups because of individual differences and histories, and social interactions (Silverman et al. 2001).

Here we develop and test a differential equation model for diurnal abundance in a local assemblage of loafing gulls. Gulls (family Laridae) constitute one of the best-studied and most cosmopolitan avian groups; their diurnal activity patterns, large sizes, and dense breeding concentrations make them convenient field subjects upon which to test ecological hypotheses
(Tinbergen 1960, Evans 1982a, Spear et al. 1998, Annett and Pierotti 1999, Good et al. 2000, Schreiber and Burger 2001). In reference to gulls, the term "loafing" is often used without precise definition but generally involves sleeping, sitting, standing, resting, defecating, and/or preening outside areas used for feeding and breeding. Gulls typically loaf in areas of good visibility (Cooke and Ross 1972, Wondolowski 2002), a tendency that often puts them in conflict with human health and safety (Wright 1968, Stout et al. 1974, Belant 1997).

Previous studies have found correlations of habitat occupancy by loafing gulls with tide, presumably because of increased food availability at low water levels, with time of day, or both (Patterson 1965, Drent 1967, Galusha and Amlaner 1978, Wondolowski 2002). Those studies found an increase in the number of loafing gulls with increasing tide, and a decrease in numbers during midday. Working from those correlations, we based our mathematical model on four hypotheses:

(H1) Fluctuations in numbers of gulls in the loafing area occur in direct response to some environmental variable $E(t)$, to be selected from the following suite of alternative subhypotheses:

(H1A) $E(t)=$ tide height

(H1B) $E(t)=1 /$ solar elevation.

(H1C) $E(t)=$ tide height / solar elevation.

$(\mathrm{H} 2)$ Number of gulls in the loafing area during daylight hours can be described with a twocompartment model consisting of the loafing area and a remote location (places other than the loafing area).

(H3) Gulls arrive at the loafing area at a per capita rate proportional to $E(t)$, and leave the loafing area at a per capita rate inversely proportional to $E(t)$.

(H4) Total number of gulls in the two-compartment system depends on the time of year and is proportional to the weekly maximal number visiting the loafing area (Fig. 1).

In the language of mathematical biology, (H1)-(H4) are called "modeling assumptions," because they are the statements that are translated into mathematical equations. It is important to note, however, that modeling assumptions are actually biological hypotheses, which are tested when the model predictions are evaluated against data.

We field tested the mathematical model resulting from (H1)-(H4) and found clear dynamic 


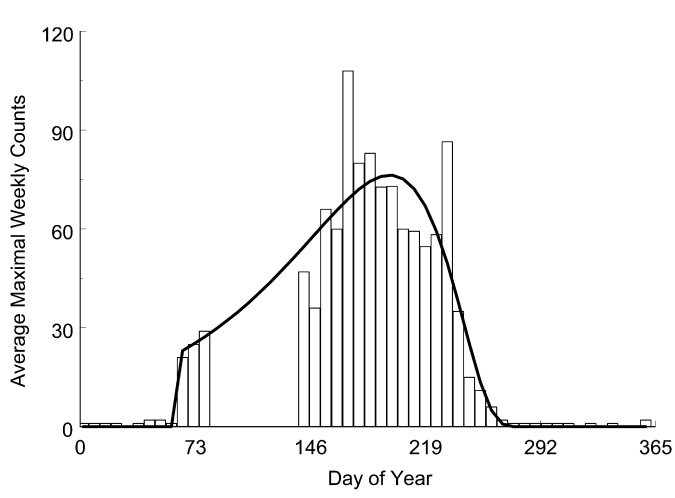

FIg. 1. Maximal historical counts at the loafing area throughout the year. Each bar represents one week of the year. Height of each bar is the mean historical maximal count recorded at the loafing area for that week, averaged over the years 1997-1999 and 2001. A modified lognormal curve was fitted through the averages to estimate the function $K_{p}(t)$. After the 275th day of the year and before the 65th day of the year, the average maximal pier counts were zeros or ones, so we set $K_{p}(t)=0$ for those intervals.

patterns for small assemblages of loafing gulls, even though individuals move in and out of the loafing area more or less continuously throughout the day. We were able to forecast, several months in advance, the number of loafing birds during each daylight hour for 29 consecutive days. We show that pattern formation at that level of assemblage can be predicted by three environmental factors: day of the year, height of the tide, and solar elevation.

\section{Methods}

Data were collected during observations of loafing Glaucous-winged Gulls (Larus glaucescens) at Protection Island National Wildlife Refuge $\left(48^{\circ} 7^{\prime} \mathrm{N}\right.$, $\left.122^{\circ} 55^{\prime} \mathrm{W}\right)$, Strait of Juan de Fuca, Washington. Violet Point, a gravel spit on the east end of the island, contains a breeding colony of $>3,000$ gulls. Both breeding and nonbreeding gulls move among several habitat patches on the spit as they engage in behaviors related to nesting, feeding, and loafing.

We chose as our study area the most well-defined and easily censused patch in the system, a pier. The pier is used extensively and exclusively for loafing by both breeding and nonbreeding gulls. It is located in a small marina that is closed to the public and experiences only intermittent human disturbance. The reason for choosing the simplest possible habitat for the study is straightforward: if the modeling methodology cannot be used to predict abundance dynamics in the simplest of habitats, there is little hope that it can be employed to predict the dynamics of more interesting and complicated habitats and systems.

Historical data.-Hourly counts of gulls loafing on the pier were made during daylight hours (0500-2000 hours) at intervals of seven days, May to August 19971999 and 2001. Hourly counts provided samples at a temporal scale appropriate for detection of tidal and diurnal periodicities (Hunt and Schneider 1987). Tides in the Strait of Juan de Fuca are semi-diurnal with strong diurnal inequalities in the lows. "Nodes" of minimal tidal amplitude occur approximately every 14 days (Fig. 2, arrows). Patterns in counts tended to recur during similar times within that bi-weekly tidal cycle.

The historical data were randomly divided into two sets: one to be used for parameter estimation, and the other to be used for an independent evaluation of the parameterized model. (Ideally, a model should be validated against a data set independent of the one used to estimate its parameters.) To preserve a variety of data patterns in each set, we divided the data by stratified random sampling. To do that, we partitioned the 14-day tidal period into approximately four quarters. We randomly selected half of the historical daily data sets from each quarter and pooled those for use in model calibration. The remaining data were reserved for the purpose of independent model validation (Fig. 2).

General mathematical model.-The mathematical formulation of hypotheses (H1)-(H4) is the standard "compartmental model" from ordinary differential equations, where the net rate of change of the number $N$ of animals on the pier is taken to be the inflow rate minus the outflow rate:

$$
\frac{d N}{d t}=[\text { inflow rate }]-[\text { outflow rate }]
$$

The inflow rate is the per capita flow rate to the pier multiplied by the number of birds in the remote location. The outflow rate is the per capita flow rate away from the pier multiplied by the number of birds on the pier. The differential equation model is therefore

$$
\begin{gathered}
\frac{d N}{d t}=\left[\alpha E(t)\left(\beta K_{p}(t)-N\right)\right]-\left[\frac{1}{\alpha E(t)} N\right] \\
0<\alpha<\infty ; 1 \leq \beta \leq 80
\end{gathered}
$$

Here $N(t)$ is the number of gulls on the pier at time $t$, where $t$ is the day of the year, including the decimal fraction at the specific time of day. Expression $\beta K_{p}(t)$ is the total number of gulls in the two-compartment system at time $t$, where $K_{p}(t)$ estimates the maximal historical observations at the pier throughout the year (Hypothesis H4). Expression $\beta K_{p}(t)-N(t)$ is the number of gulls at the remote location at time $t$. Constants of proportionality $\alpha, \beta>0$ are parameters that must be estimated from the historical data. Maximal number of gulls in the surrounding colony is $\sim 60 \times$ the 


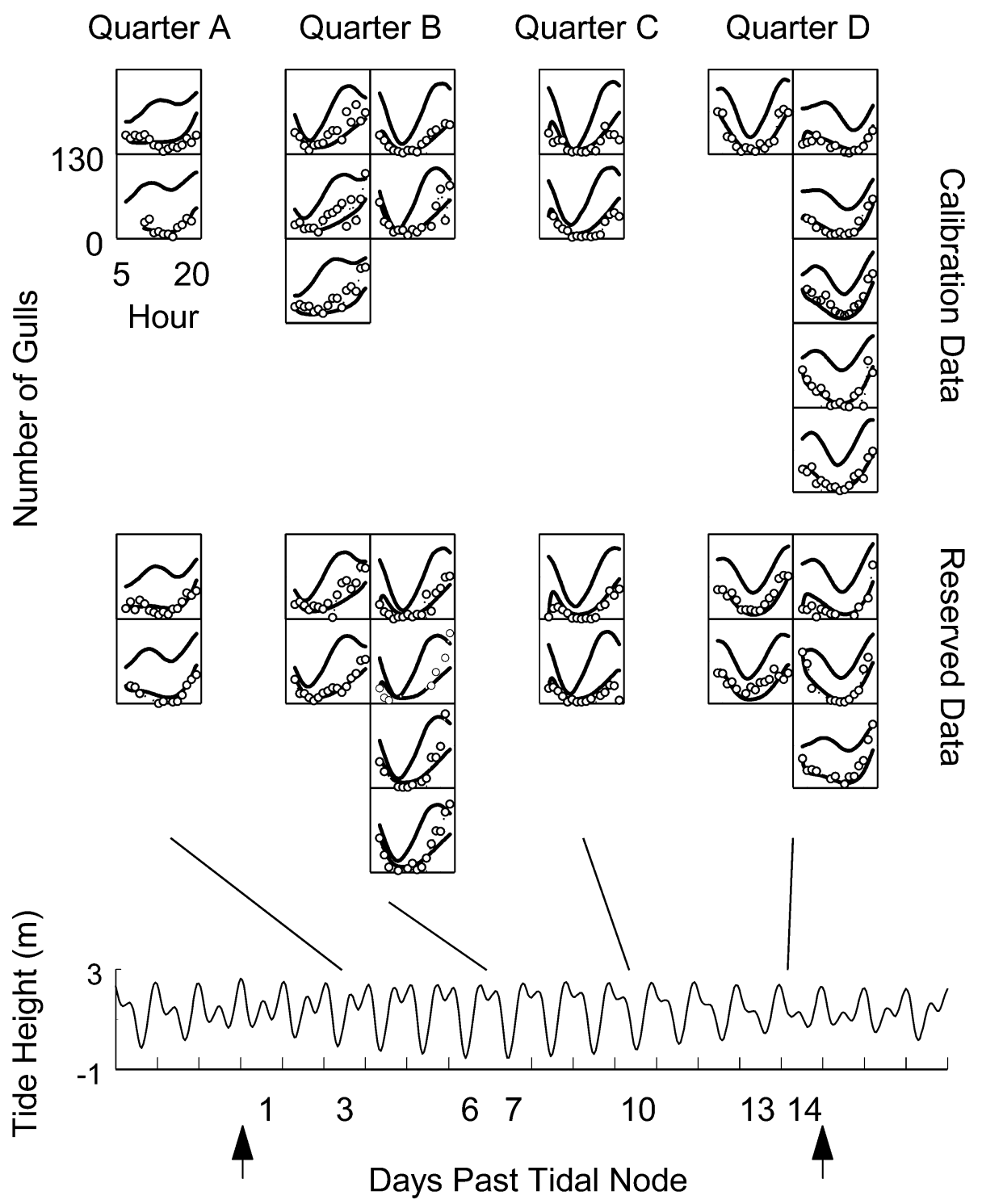

FIG. 2. Tidal-solar model prediction (lower curve), historical data (circles), and tidal curve (upper curve). Each panel corresponds to one day. Tide height is graphed on a vertical scale of -1 to $3 \mathrm{~m}$. Initial condition for each day's model prediction was taken to be the first data point collected that day. A typical tidal sequence for Protection Island is shown at the bottom; tidal nodes are indicated with arrows. Data from days occurring during the same quarter of the tidal sequence are stacked vertically. Data in a given column show similar diurnal patterns. Conditioned least-squares (CLS) parameters were estimated from the "calibration data." The "reserved data" were used to independently validate model performance without re-estimating parameters. The CLS parameter estimates appear in Table 1. Following are dates for days in each of the six columns, left to right, top to bottom: first column, 21 July 1999, 18 August 1999, 7 July 1999, 4 August 1999; second column, 2 July 1997, 16 July 1997, 13 August 1997, 30 July 1997, 5 August 1998; third column, 23 May 2001, 22 July 1998, 6 June 2001, 20 June 2001, 4 July 2001, 8 July 1998; fourth column, 14 July 1999, 28 July 1999, 30 June 1999, 11 August 1999; fifth column, 23 July 1997, 9 July 1997, 6 August 1997; sixth column, 30 May 2001, 13 June 2001, 15 July 1998, 29 July 1998, 12 August 1998, 27 June 2001, 11 July 2001, 1 July 1998. 
maximal value of $K_{p}(t)$, so we chose 80 as a generous upper bound for $\beta$.

We estimated $K_{p}(t)$ directly from historical pier data sampled throughout January 1 to March 21 and May 23 to December 31 for the years 1997-1999 and 2001 (J. L. Hayward et al. unpubl. data). From those data, we estimated seasonal maxima for the oscillating pier counts by fitting a modified lognormal curve

$$
K_{p}(t)=76.36 \exp \left[\frac{\left[\ln \left(40.29-\frac{t}{168}\right)-2.504\right]^{2}}{-0.7225}\right]
$$

through the averages, for each week of the year, of the maximal pier counts (Fig. 1). After the 275th day of the year and before the 65th day of the year, the average maximal pier counts were zeros or ones, so we set $K_{p}(t)=0$ for those intervals.

We cannot seek a solution to Equation 1 via analytic integration because of the lack of formulas for tide height and solar elevation. Rather, we estimate solutions via numerical integration, using tidal and solar data from the National Oceanic and Atmospheric Administration (NOAA), as described below. The use of an additional independent parameter (other than $1 / \alpha$ ) for the outflow term in Equation 1 did not significantly increase model performance. Silverman and Kot (2000) have used similar compartmental models for habitat patch occupancy by waterfowl.

Alternative models. - The three alternative hypotheses (H1A)-(H1C) correspond to three alternative mathematical models. For (H1A), we let $E(t)=T(t)$, where $T(t)$ is tide height normalized so that $1 \leq T(t)$ $\leq 2$; for $(\mathrm{H} 1 \mathrm{~B})$, we let $E(t)=1 / S(t)$, where $S(t)$ is solar elevation with negative elevations set to zero, and $S(t)$ is normalized so that $1 \leq S(t) \leq 2$; and for (H1C), we let $E(t)=T(t) / S(t)$. Solar elevation and tide height predictions were obtained from NOAA (see Acknowledgments). When substituted into Equation 1 , the three alternative hypotheses generate three specific alternative models that we designate the "tidal model," "solar model," and "tidal-solar model," respectively. We did not try all combinations of $S(t)$ and $T(t)$ as hypotheses; in fact, there are infinitely many such combinations. The three we chose were hypothesized from correlations in studies done by other researchers, as explained earlier.

Model parameterizations.-Parameters for each of the three alternative models were estimated from the historical calibration data using the method of conditioned least squares (CLS). In that method, the model to be parameterized is used to produce hourly onestep predictions of the next observation, conditioned on the previous observation. That is, for a set of $n+1$ successive hourly observations $\left\{x_{0}, x_{1}, \ldots, x_{n}\right\}$, the model is used to produce $n$ hourly one-step predictions $\left\{y_{1^{\prime}}\right.$ $\left.y_{2}, \ldots, y_{n}\right\}$, where $y_{i+1}$ denotes the model prediction at time $i+1$, given the observation $x_{i}$ at time $i$ as the initial condition for the model. The conditioned onestep residual errors are given by the differences $y_{i}-x_{i}$ between the predicted and observed values at time $i$. The CLS method (as opposed to maximal-likelihood methods) relaxes many of the assumptions about the distribution of the residual errors (Dennis et al. 2001). The residual sum of squares

$$
R S S(\theta)=\sum_{i=1}^{n}\left(y_{i}-x_{i}\right)^{2}
$$

is minimized as a function of the vector $\theta$ of model parameters; the minimizer $\hat{\theta}$ is the vector of CLS parameter estimates for the model. We produced the onestep predictions with the MatLab ODE integrator and minimized $\operatorname{RSS}(\theta)$ with a Nelder-Mead algorithm. The Nelder-Mead algorithm is a convenient method for numerically finding minima of functions (see Olsson and Nelson 1975, Press et al. 1986). The CLS parameter estimates for each model appear in Table 1.

Model selection. - We used three criteria to compare the three parameterized models on the calibration data set: the residual sum of squares $R S S(\hat{\theta})$ at the estimated parameter values, the goodness-of-fit as measured by $R^{2}$, and the Akaike Information Criterion (AIC) (Burnham and Anderson 2002). Goodness-of-fit as measured by $R^{2}$ is given by

$$
R^{2}=1-\frac{R S S(\hat{\theta})}{\sum_{i=1}^{n}\left(x_{i}-\bar{x}\right)^{2}}
$$

where $\bar{x}$ denotes the sample mean of the observations $\left\{x_{1}, x_{2}, \ldots, x_{\mathrm{n}}\right\}$. The statistic $R^{2}$ estimates the proportion of the observed variability that is explained by the

TABLE 1. Model selection on historical calibration data. Conditioned least-squares (CLS) parameters $\alpha$ and $\beta$ were estimated for three alternative models using the historical calibration data; the variance parameter $\sigma^{2}$ of the likelihood function was estimated from the residuals. The CLS parameters for the solar model occur on the boundary $\beta=80$ of the feasible parameter range; with no restriction on $\beta$, the minimizer occurs at $\beta=$ $\infty$. All three models are ranked in the same order by each of $R S S, R^{2}$, and AIC. The tidal and solar models are discarded in favor of the tidal-solar model.

\begin{tabular}{lcccccccc}
\hline \hline Model & $\hat{\alpha}$ & $\hat{\beta}$ & $\hat{\sigma}^{2}$ & $n$ & $\kappa$ & $R S S$ & $R^{2}$ & AIC \\
\hline Tidal model & 0.307 & 1.97 & 245 & 205 & 3 & 50149 & 0.38 & 1133 \\
Solar model & 0.0985 & 80.0 & 225 & 205 & 3 & 46084 & 0.43 & 1116 \\
Tidal-solar model & 0.349 & 2.85 & 167 & 205 & 3 & $\mathbf{3 4 1 9 5}$ & $\mathbf{0 . 5 8}$ & $\mathbf{1 0 5 5}$ \\
\hline
\end{tabular}


model and thus gives a measure of the accuracy of the model predictions. The AIC is an informationtheoretic model selection index designed to select the model closest to the "truth" from a suite of alternative models (Peek et al. 2002). For the CLS method, the criterion is equivalent to

$$
\mathrm{AIC}=n \ln \hat{\sigma}^{2}+2 \kappa
$$

where $n$ is the number of observations, $\hat{\sigma}^{2}=R S S(\hat{\theta}) / n$ is the variance of the likelihood function as estimated from the residuals, and $\kappa$ is the number of model parameters, including $\sigma^{2}$ (Burnham and Anderson 2002). All three of our alternative models contain two parameters $\alpha$ and $\beta$, and so with $\sigma^{2}$ we have $\kappa=3$ in each case. The actual value of AIC, which can be positive or negative, does not give any information. Rather, model comparison is based on the relative differences between and the rank of the AIC values for the suite of alternative models. The smallest AIC value indicates the model closest to "truth."

\section{Results}

All three criteria gave the same model ranking (Table 1), and we discarded the tidal and solar models in favor of the tidal-solar model. Simulations of the tidal-solar model, along with the calibration data, are shown in Figure 2.

Model validation.-We used the reserved historical data to independently evaluate the performance of the selected model without reestimating its parameters. Specifically, we evaluated the tidal-solar model, as parameterized with the calibration data, by computing its goodness-of-fit $R^{2}$ for the historical reserved data. The goodness-of-fit for the reserved data was $R^{2}=0.61$, a value comparable to the goodness-of-fit of $R^{2}=0.58$ for the calibration data. That correspondence supported model validation. Model simulations for the reserved data appear in Figure 2.

Model predictions. - To further validate the tidal-solar model, we generated (before our arrival on Protection Island) a priori hourly predictions for numbers of gulls on the pier in daylight for May and early June, the beginning of the 2002 breeding season (Fig. 3). The model forecast periodicities at three temporal scales: high-frequency daily oscillations (Fig. $4 C$ ), the expected low-frequency seasonal oscillation (Fig. 4A), and an unexpected mediumfrequency oscillation (Fig. 4C) coinciding with a bi-weekly tidal pattern (Fig. 4E, arrows). The shapes and minimal values of the predicted daily fluctuations depended in an unintuitive way on the temporal location within the tidal cycle with respect to the solar cycle (Figs. 3 and $4 C)$. For example, on some days coinciding with a tidal node, predictions fluctuated out of phase with the tide (Fig. 3, days 142 and 155), a surprising prediction in light of previous studies.

Test of model predictions. - Data collection to test the predictions began at 0900 on 9 May 2002, continued at hourly intervals from dawn

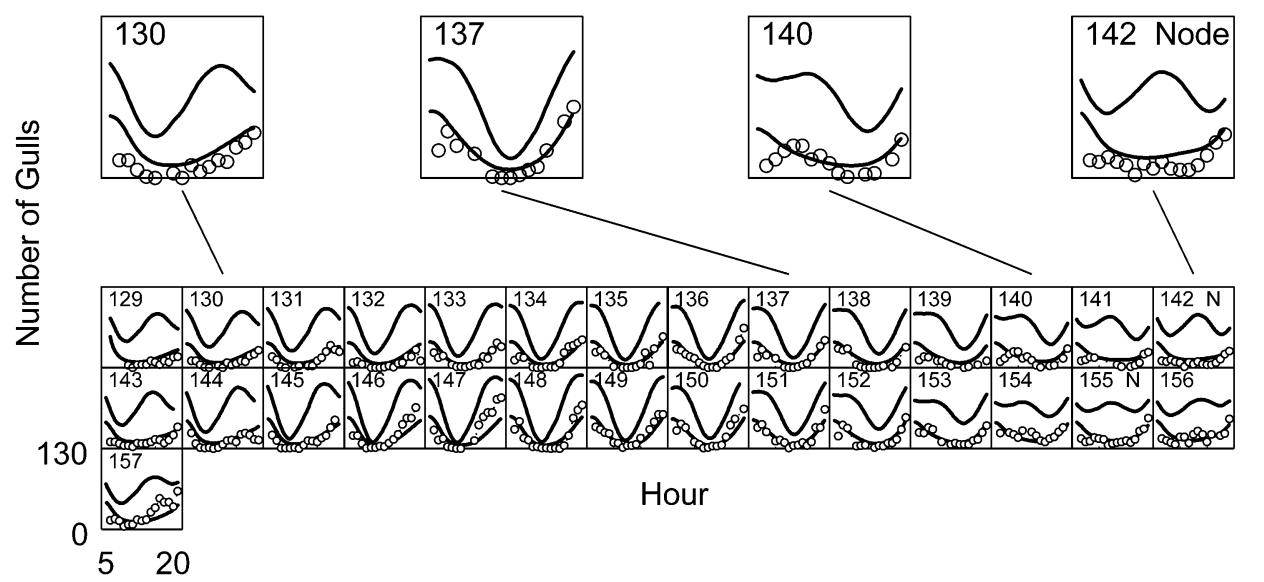

FIG. 3. Tidal-solar model prediction (lower curve), data from spring 2002 (circles), and tidal curve (upper curve). Tide height is graphed on a vertical scale of -1 to $3 \mathrm{~m}$. Each daily panel is identified with the day of the year. The model prediction was not reinitialized for each day but rather was run continuously for all 29 days. Each row of 14 panels corresponds to one two-week tidal cycle. Tidal nodes (N) occur on or near days 142 and 155. Each column of panels contains similar patterns in data. The CLS parameter values appear in Table 1. 

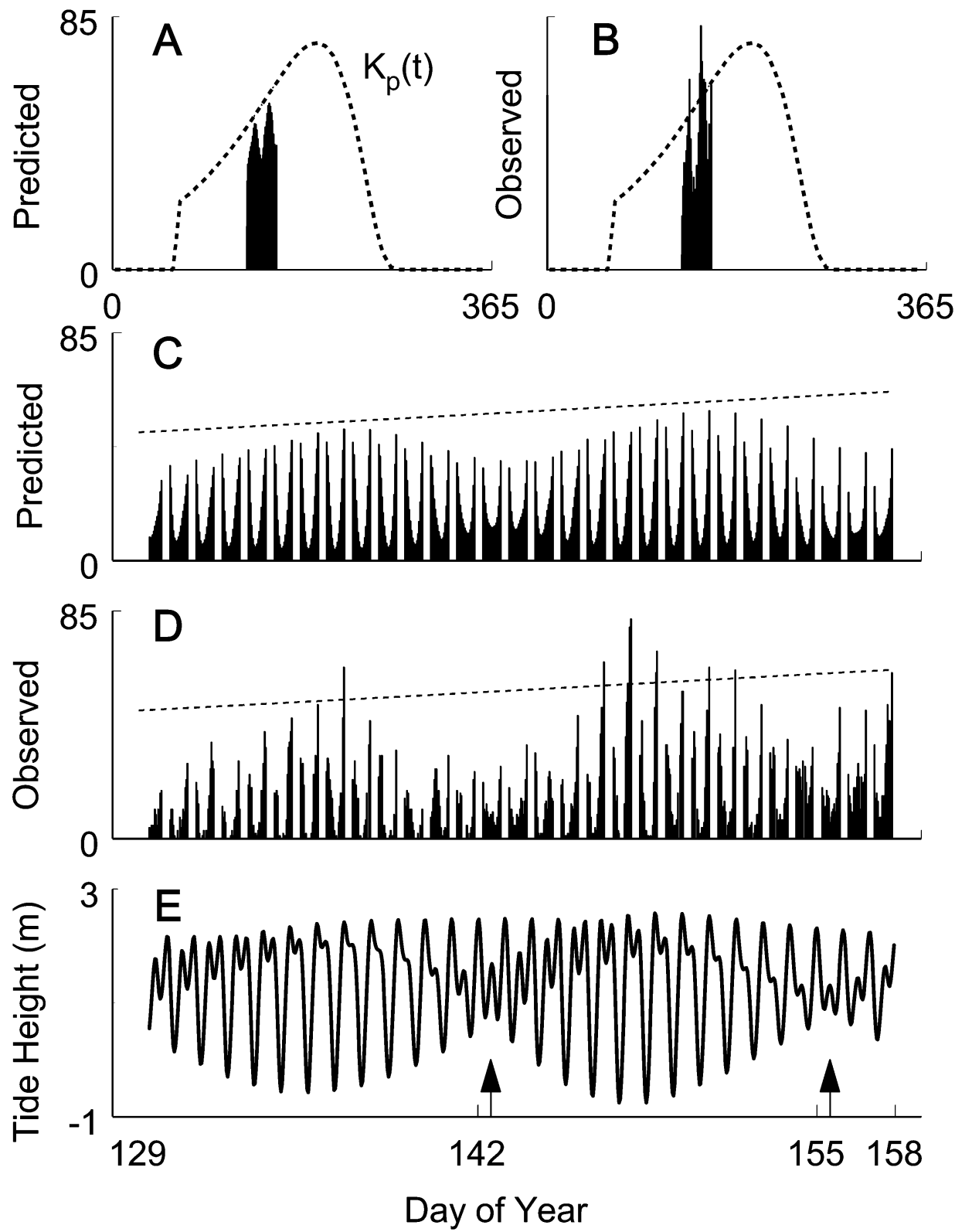

Fig. 4. Tidal-solar model predicted oscillations on three different time scales. The dotted curves show the seasonal oscillation $K_{p}(t)$. (A, C) Model predictions for the spring of 2002. Oscillations are present on daily, biweekly, and yearly scales. (B, D) Data observations corresponding to the predictions in (A) and (C). (E) Tidal oscillation for the data collection time period in 2002. Tidal nodes are indicated with arrows.

to dusk (0500-2000) until 2000 on 6 June 2002, and traversed two consecutive tidal nodes. Counts of the number of gulls on permanent structures associated with the pier were made from a 30-m high cliff located $100 \mathrm{~m}$ from the pier. Counts for which there was a human disturbance at the pier within $30 \mathrm{~min}$ before or during a count were eliminated. The model was not reparameterized with the new data; all of our predictions and analysis are based on the 
parameters estimated from the historical calibration data set.

All three predicted periodicities were represented in the 2002 data (Fig. 4B,D). Model predictions closely approximated daily counts, both qualitatively (Fig. 3) and quantitatively, as measured by a goodness-of-fit of $R^{2}=0.66$. During each internodal period, daily minimal gull counts lagged morning low-low tides during the first several days (e.g. Fig. 3, day 130), shifted to a point below midday low-low tides mid-period (e.g. Fig. 3, day 137), preceded afternoon low-low tides later in the period (e.g. Fig. 3 , day 140), and finally coincided with high tide at the node (e.g. Fig. 3, day 142). Moreover, daily maximal gull counts increased after the node, then decreased toward the next node reflecting the predicted bi-weekly oscillation (Fig. 4B,D). Finally, average daily counts increased from the first to the second bi-weekly oscillation period reflecting the expected increase in numbers during the spring (Fig. 4B,D).

The model does not account for dynamics during dusk and dawn; at those times, the system seemed to be driven by light intensity. Counts began to match model predictions $\sim 1 \mathrm{~h}$ past sunrise. Attendance by gulls at the pier was extended on moonlit nights. Departures of data from model predictions may be partly accounted for by (1) human disturbances at the pier, (2) low light intensity during many early morning counts, (3) number of boats tied to the pier (creating changes in visibility and available loafing areas), (4) Bald Eagle (Haliaeetus leucocephalus) flyovers (Galusha and Hayward 2002), (5) count inaccuracies because of fog, and (6) weather variables (temperature, wind speed and direction, rain). Greater than predicted counts on days 154, 156, and 157 may indicate higher order effects of tide.

\section{Discussion}

Short-term fluctuations in animal numbers by habitat reflect a diversity of competing functional needs (DeWoskin 1980, Cody 1985, Walsberg 1985). In the course of a single day, for example, an individual bird may bathe, feed, incubate, and loaf. To complete those behaviors, the bird must shift from habitat to habitat several times (Cooke and Ross 1972, Wondolowski 2002). Environmental factors and physiological constraints play important roles in opening and closing opportunities for those behaviors (Walsberg 1985, Hunt and Schneider 1987). For example, because gulls depend on vision to orient and feed, darkness precludes foraging activity; and, because food is exposed at low tides, foraging would be expected to increase at those times. Thus, accurate prediction of habitat occupancy in relation to tide and time of day might appear to be a trivial or uninteresting exercise, and the reader may wonder about the necessity of such comprehensive methodology. At least three considerations should be kept in mind.

First, gulls are complex animals that exhibit considerable individual variation. A single gull makes decisions about when to move from one habitat to another, all within the context of a unique set of historical contingencies. Although decisions to enter or leave the habitats by one gull maybe be influenced by behaviors of other gulls (Evans 1982b, Wittenberger and Hunt 1985, Götmark et al. 1986), those decisions also may be made independently. Except for collective flights in response to human disturbance, we detected no evidence of social facilitation or coaction in arrivals and departures from the loafing area; gulls arrived and departed individually throughout the day, leading us to think that the decision to loaf may be relatively independent of the actions of other gulls. (By contrast, gulls moving to and from feeding sites commonly flew in groups.) Other studies have stochastically modeled the movement of waterfowl between habitat patches and found that $\sim 70 \%$ moved singly, whereas $\sim 20 \%$ moved in pairs (Silverman et al. 2001). The fact that accurate mathematical prediction for the dynamics of an assemblage of animals is possible suggests that stochastic individual variability may be less important than deterministic forces at some scales of group behavior (Levin 1992).

Second, the modeling methodology uncovered (and the model accurately predicted) two unexpected outcomes that would have been difficult to forecast and quantify with correlative studies alone: a counterintuitive increase in gull counts at the pier during low tides around tidal nodes, and a medium-frequency biweekly oscillation in counts. That suggests that the mathematical superposition of environmental oscillations such as tide, time of day, and time of season can cause predictable patterns of aggregate behavior. 
Third, we reiterate the need for accurate dynamical models for field systems in ecology and emphasize that the methodology outlined here should first be applied successfully to "simple" field systems before it is applied to more complicated systems (Dennis et al. 2001). Our continuing studies focus on the development of a predictive model for the entire system of habitat patches associated with the Protection Island breeding colony. The success of such a program is predicated, however, upon rigorous and successful application of the modeling methodology to simple, well-defined constituents of the system, as we have done here.

The ability to predict the dynamics of organisms in nature has broad implications for pressing world problems including the spread of disease, food production, conservation of species diversity, and resource management (Hastings and Palmer 2003). Mathematical models can provide testable hypotheses, but only if data are rigorously tied to models through parsimonious modeling assumptions and appropriate statistical techniques of model parameterization, model selection from a suite of alternatives, and model validation. Data must be sampled sufficiently densely to allow for proper model parameterization and validation. Our initial detection of patterns in the historical data and subsequent modeling of dynamics were successful because we field-sampled at intervals smaller than the environmental periodicities involved (Hunt and Schneider 1987, Levin 1992). Furthermore, models should be parameterized and validated on independent data sets; otherwise "modeling" becomes simply an exercise in curve fitting and has little explanatory power. Finally, the best mathematical models not only describe and explain, but also predict. Therefore, testing a priori model predictions provides the most satisfying evidence that the model captures the major dynamics of the system, especially if the predictions are unexpected.

We make one final comment about the tidal-solar model. The prediction $N(t)$ of a differential equation model is normally obtained by integrating over the past. However, because this system recovers rapidly after disturbance, it can be shown that the state of the system depends primarily on the environmental variables at the time $t$ for which prediction is desired. More specifically, the tidal-solar model with the estimated parameter values has fast transient dynamics; recovery from disturbance requires $<1 \mathrm{~h}$, according to both the model and our observations. Multiple time scale analysis (Lin and Segel 1988) shows that the solution of the tidal-solar model is well approximated by

$$
N_{o}(t)=\frac{\beta K_{p}(t)}{1+\frac{1}{\alpha^{2}}\left(\frac{S(t)}{T(t)}\right)^{2}}
$$

when the transients are removed. Roughly speaking, the approximation is accurate with respect to the differential equation model to within one bird during 0600-1700 hours, to within two birds at 0500 hour, and to within five birds at 2000 hour, when the error is greatest $(\sim 12 \%)$. Although the algebraic Equation 2 is more tractable than the differential Equation 1 , it cannot account for transient dynamics after disturbances and therefore should not be used to produce conditional one-step predictions for the parameterization and validation techniques used here. However, the fact that the "steady state" dynamics of such a system can be well predicted by a simple algebraic formula is surprising and should be of particular interest to resource managers.

Conclusion.-Seabirds occupy environments that exhibit a high degree of scale-dependent spatial and temporal heterogeneity. A primary goal of seabird studies is to understand how the animals distribute themselves in relation to that heterogeneity (Hunt and Schneider 1987). Here we have shown that the number of gulls occupying a dedicated loafing habitat can be predicted at any particular time by specifying the day of the year, the solar elevation, and the height of the tide. We find it intriguing that, in the midst of complex and apparently asynchronous individual activity, aggregate behavior can be accurately predicted by simple algebraic rules.

\section{Acknowledgments}

We thank R. Edens, J. Takekawa, and K. Ryan, U.S. Department of the Interior, Fish and Wildlife Service, for permission to work on Protection Island National Wildlife Refuge; Walla Walla College Marine Station for logistical support; C. Bové, J. Brady, C. Moffett, D. Moffett, and W. Odegard for field assistance; and R. F. Costantino, J. M. Cushing, B. Dennis, R. A. Desharnais, F. C. Hoppensteadt, M. W. Meyer, and W. M. Schaffer for discussions. Solar elevation and tide 
height predictions were obtained from NOAA at http: //www.srrb.noaa.gov/highlights/sunrise/azel.html and http://co-ops.nos.noaa.gov, respectively. This research was supported by Andrews University faculty grants and National Science Foundation grant DMS 0314512.

\section{Literature Cited}

Annett, C. A., And R. Pierotti. 1999. Longterm reproductive output in Western Gulls: Consequences of alternate tactics in diet choice. Ecology 80:288-297.

Belant, J. L. 1997. Gulls in urban environments: Landscape-level management to reduce conflict. Landscape and Urban Planning 38: 245-258.

Burnham, K. P., and D. R. Anderson. 2002. Model Selection and Multi-Model Inference: A Practical Information-Theoretic Approach, 2nd ed. Springer, New York.

Cody, M. L. 1985. An introduction to habitat selection in birds. Pages 3-56 in Habitat Selection in Birds (M. L. Cody, Ed.). Academic Press, Orlando, Florida.

Coокe, F., AND R. K. Ross. 1972. Diurnal and seasonal activities of a post-breeding population of gulls in southeastern Ontario. Wilson Bulletin 84:164-172.

Cushing, J. M., R. F. Costantino, B. Dennis, R. A. Desharnais, and S. M. Henson. 1998. Nonlinear population dynamics: Models, experiments, and data. Journal of Theoretical Biology 194:1-9.

Cushing, J. M., R. F. Costantino, B. Dennis, R. A. Desharnais, and S. M. Henson. 2003. Chaos in Ecology: Experimental Nonlinear Dynamics. Academic Press, San Diego, California.

Dennis, B., R. A. Desharnais, J. M. Cushing, S. M. Henson, and R. F. Costantino. 2001. Estimating chaos and complex dynamics in an insect population. Ecological Monographs 71: 277-303.

DeWoskin, R. 1980. Heat exchange influence on foraging behavior in Zonotrichia flocks. Ecology 61:30-36.

Drent, R. H. 1967. Functional aspects of incubation in the Herring Gull (Larus argentatus Pont.). Behaviour Supplement 17.

Evans, R. M. 1982a. Flock size formation in Blackbilled Gulls. Canadian Journal of Zoology 60: 1806-1811.

Evans, R. M. 1982b. Foraging-flock recruitment at a Black-billed Gull colony: Implications for the Information Center hypothesis. Auk 99:24-30.

Galusha, J. G., And C. J. Amlaner. 1978. The effects of diurnal and tidal periodicities in the numbers and activities of Herring Gulls Larus argentatus in a colony. Ibis 120:322-328.
Galusha, J. G., And J. L. Hayward. 2002. Bald Eagle activity at a gull colony and seal rookery on Protection Island, Washington. Northwestern Naturalist 83:23-25.

Good, T. P., J. C. Ellis, C. A. Annett, and R. Pierotti. 2000. Bounded hybrid superiority in an avian hybrid zone: Effects of mate, diet, and habitat choice. Evolution 54:1774-1783.

Götmark, F., D. W. Winkler, and M. Andersson. 1986. Flock-feeding of fish schools increases individual success in gulls. Nature 319:589-591.

Hastings, A., And M. A. PAlmer. 2003. Mathematics and biology: A bright future for biologists and mathematicians? Science 299:2003-2004.

Hunt, G. L., JR., AND D. C. Schneider. 1987. Scale-dependent processes in the physical and biological environment of marine birds. Pages 7-41 in Seabirds: Feeding, Ecology and Role in Marine Ecosystems (J. P. Croxall, Ed.). Cambridge University Press, Cambridge, United Kingdom.

Levin, S. A. 1992. The problem of pattern and scale in ecology. Ecology 73:1943-1967.

Lin, C. C., ANd L. A. Segel. 1988. Mathematics Applied to Deterministic Problems in the Natural Sciences. Society for Industrial and Applied Mathematics, Philadelphia.

Olsson, D. M., And L. S. Nelson. 1975. The NelderMead simplex procedure for function minimization. Technometrics 17:45-51.

Patterson, I. J. 1965. Timing and spacing of broods in the Black-headed Gull Larus ridibundus L. Ibis 107:433-459.

Peek, J. M., B. Dennis, And T. Hershey. 2002. Predicting population trends of mule deer. Journal of Wildlife Management 66:729-736.

Press, W. H., B. P. Flannery, S. A. Teukolsky, and W. T. Vetterling. 1986. Numerical Recipes: The Art of Scientific Computing. Cambridge University Press, Cambridge, United Kingdom.

Schreiber, E. A., And J. Burger, Eds. 2001. Biology of Marine Birds. CRC Press, Boca Raton, Florida.

Silverman, E., ANd M. Кот. 2000. Rate estimation for a simple movement model. Bulletin of Mathematical Biology 62:351-375.

Silverman, E. D., M. Kot, and E. Thompson. 2001. Testing a simple stochastic model for the dynamics of waterfowl aggregations. Oecologia 128:608-617.

Spear, L. B., P. Pyle, and N. Nur. 1998. Natal dispersal in the Western Gull: Proximal factors and fitness consequences. Journal of Animal Ecology 67:165-179.

Stout, J. F., J. L. Hayward, and W. H. Gillett. 1974. Aggregations of gulls (Laridae) on aerodromes and behavioral techniques for dispersal. Pages 125-148 in Proceedings of the Conference on 
the Biological Aspects of the Bird/Aircraft Collision Problem (J. P. Croxall, Ed.). Clemson University, Clemson, South Carolina.

Tinbergen, N. 1960. The Herring Gull's World. Harper and Row, New York.

Turchin, P. 1998. Quantitative Analysis of Movement: Measuring and Modeling Population Redistribution in Animals and Plants. Sinauer Associates, Sunderland, Massachusetts.

Walsberg, G. E. 1985. Physiological consequences of microhabitat selection. Pages 389-413 in Habitat Selection in Birds (M. L. Cody, Ed.). Academic Press, Orlando, Florida.

Wiens, J. A. 1976. Population responses to patchy environments. Annual Review of Ecology and Systematics 7:81-120.
Wittenberger, J. F., and G. L. Hunt, Jr. 1985. The adaptive significance of coloniality in birds. Pages 1-78 in Avian Biology, vol. 8 (D. S. Farner, J. R. King, and K. C. Parkes, Eds.). Academic Press, Orlando, Florida.

WonDolowsKI, L. 2002. Diurnal activity patterns of wintering gulls at Jug Bay Wetlands Sanctuary, Maryland. M.S. thesis, Bard College, Annandale-on-Hudson, New York.

Wright, E. N. 1968. Modification of the habitat as a means of bird control. Pages 97-105 in The Problems of Birds as Pests (R. K. Murton and E. N. Wright, Eds.). Academic Press, New York.

Associate Editor: A. E. Burger 